
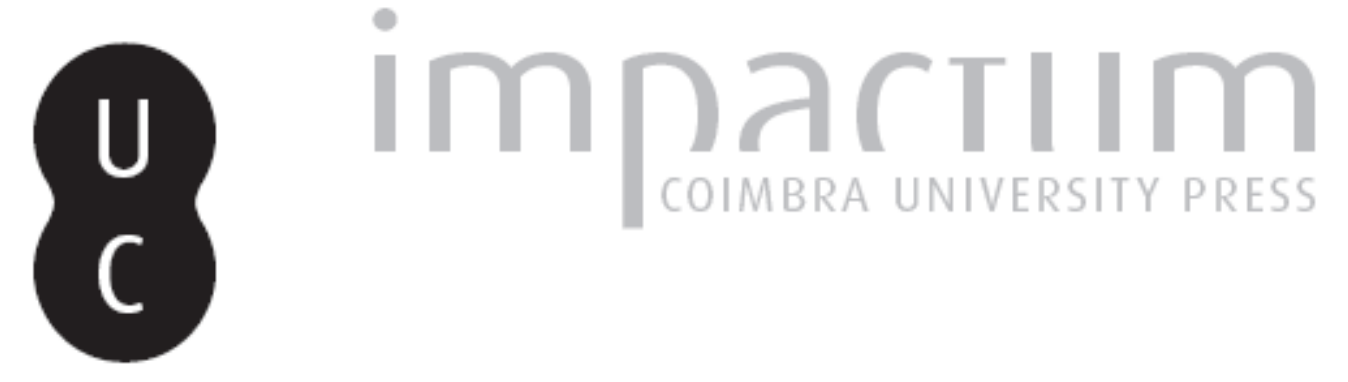

\title{
Literatura de la memoria y la búsqueda de la identidad: América en las escrituras digitales del yo de los autores emigrados a España
}

Autor(es): $\quad$ Escandell Montiel, Daniel

Publicado por: Centro de Literatura Portuguesa; Imprensa da Universidade de Coimbra

URL

persistente:

URI:http://hdl.handle.net/10316.2/38730

DOI:

DOI:http://dx.doi.org/10.14195/2182-8830_4-1_7

Accessed : $\quad$ 26-Apr-2023 15:21:45

A navegação consulta e descarregamento dos títulos inseridos nas Bibliotecas Digitais UC Digitalis, UC Pombalina e UC Impactum, pressupõem a aceitação plena e sem reservas dos Termos e Condições de Uso destas Bibliotecas Digitais, disponíveis em https://digitalis.uc.pt/pt-pt/termos.

Conforme exposto nos referidos Termos e Condições de Uso, o descarregamento de títulos de acesso restrito requer uma licença válida de autorização devendo o utilizador aceder ao(s) documento(s) a partir de um endereço de IP da instituição detentora da supramencionada licença.

Ao utilizador é apenas permitido o descarregamento para uso pessoal, pelo que o emprego do(s) título(s) descarregado(s) para outro fim, designadamente comercial, carece de autorização do respetivo autor ou editor da obra.

Na medida em que todas as obras da UC Digitalis se encontram protegidas pelo Código do Direito de Autor e Direitos Conexos e demais legislação aplicável, toda a cópia, parcial ou total, deste documento, nos casos em que é legalmente admitida, deverá conter ou fazer-se acompanhar por este aviso.

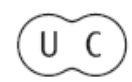




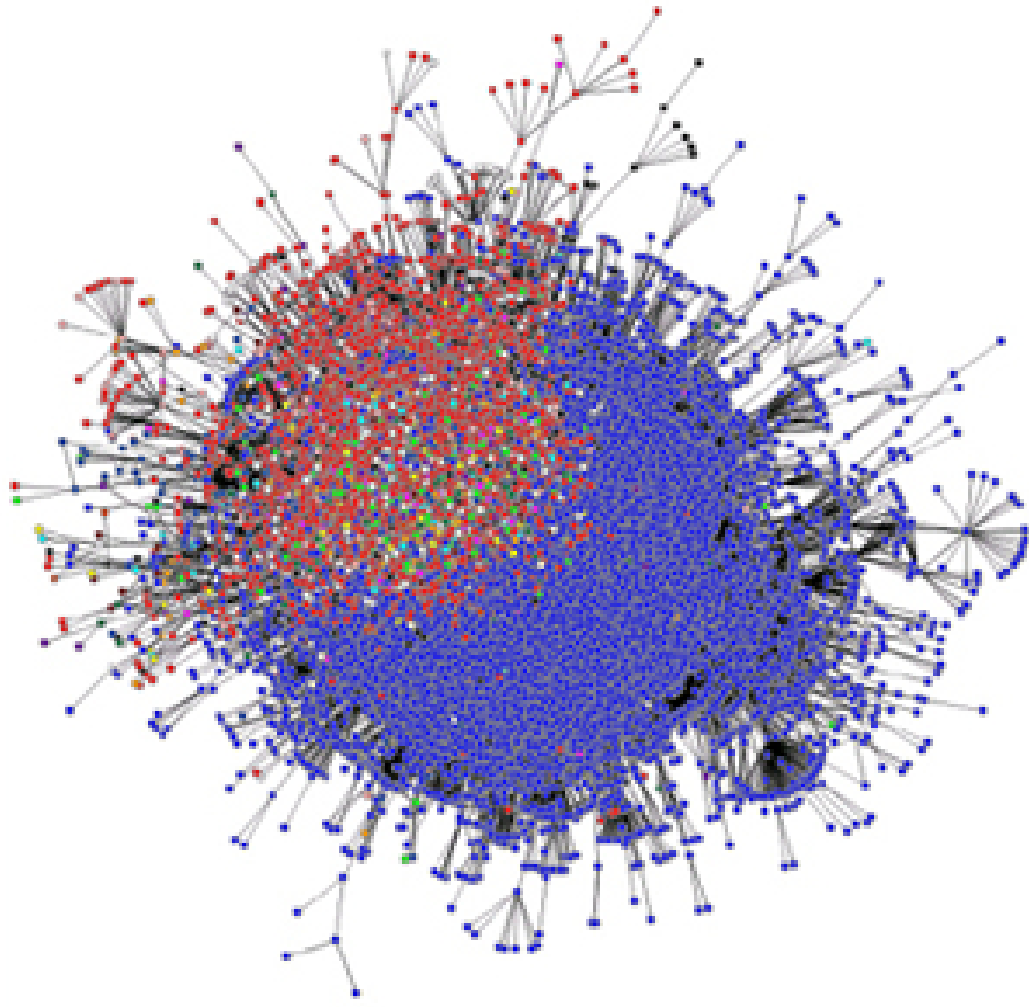

Vol. 4.1 (2016) ISSN 2182-8830

'Estudos Literários Digitais 1'

Manuel Portela e António Rito Silva (orgs.) 


\title{
Literatura de la Memoria y la Búsqueda de la Identidad: América en las Escrituras Digitales del Yo de los Autores Emigrados a España \\ DANIEL ESCANDELL MONTIEL \\ Universidad de Valladolid
}

\begin{abstract}
Resumen
La literatura digital y, en particular, la blogoficción, puede ser uno de los recursos narrativos para la construcción de una memoria del emigrado y del discurso social de la diáspora. Esto se debe a la potencia testimonial de la narrativa del yo, en la que se encuadran las blogoficciones a través de sus diferentes recursos de avatarización. En este artículo analizamos la posibilidad de un discurso de la diáspora en la literatura en línea a través de la obra de autores de origen latinoamericano que crean y publican su obra en la red lejos de su tierra natal, desde España con la intención de explorar la creación de una voz literaria propia a través del avatar como vía para la cicatrización emocional del proceso memorístico. Palabras clave: diaspora; memoria; blogoficción; narrativa digital; avatar; literatura latinoamericana.
\end{abstract}

\section{Abstract}

Digital literature and, in particular, blogfiction, can be one of the narrative devices used to build a memory of the emigrant and the social discourse of the diaspora. This is due to the testimonial potential of the narratives of the self, in which blogfictions are framed by means of their different avataric resources. The present article analyzes the possibility of a discourse of diaspora in online literature through the work of Latin-American authors who create and publish their work on the Internet away from their homeland, from Spain, with the intention of exploring the creation of a literary voice through the avatar itself as a resource for the of emotional healing of the memorial process. Keywords: diaspora; memory; blogfiction; digital narrative; avatar; Latin-American literature.

\section{Introducción}

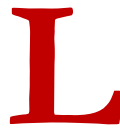

a relación de los movimientos migratorios entre España y América ha estado muchas veces condicionada por la situación política, económica y social de los diferentes territorios, pero en cualquier caso se ha caracterizado por lo fluido del tránsito (dentro de lo que esos elementos externos podían permitir) de escritores entre ambos lados del Atlántico. En las primeras décadas del siglo XXI se está viviendo una situación de normalización general, con excepciones, que no deben hacernos olvidar que se ha vivido hasta muy recientemente una victimización clara 
asociada a la emigración de quienes huyeron de España y de no pocos países en América hacia España.

Poca duda cabe de que las literaturas de España e Hispanoamérica han estado fuertemente condicionadas $-\mathrm{y}$, en el caso de la literatura en español escrita en Hispanoamérica, casi desde sus orígenes- por un impulso de restitución de la memoria, de la dignidad y de la damnificación. ${ }^{1}$ Se trata, además, de una relación compleja que es paralela a la Portugal y los demás países lusófonos. En el mundo actual, lo cierto es que muchos (y nos atrevemos a decir que la inmensa mayoría) de los autores de origen hispanoamericano tienen la libertad para volver a su país si así lo desean: dicho de otra manera, no se sitúan en la figura del refugiado político o el exiliado (al menos, no el forzoso), lo que conduce a relaciones normalizadas con sus países de origen. Por supuesto, no pretendemos aquí excluir a quienes se hayan sentido expulsados de su país de origen o excluidos de su sociedad, ni fingir que hay una normalidad democrática y de respeto a las libertades en la totalidad del mundo hispano, ${ }^{2}$ pero sí es posible afirmar que en la fecha actual la democracia y las libertades son hechos comunes y muy establecidos en la inmensa mayoría del territorio.

Por tanto, estaríamos hablando —en la mayoría de los casos actualesde escritores hispanoamericanos afincados en España de una creación literaria que se asienta mucho más en la nostalgia que en el duelo del exilio, al menos no desde una posición objetiva. Desde la subjetividad, puede haber autores que se sientan exiliados o que lo sean de facto, pues quiénes somos para juzgar la relación individuo-patria y las razones por las que cada uno decide dejar atrás su lugar de nacimiento. Se trata, en cualquier caso, de una literatura de la diáspora que no es, por supuesto, uniforme ni homogénea en la totalidad del continente americano, pero que sí ha sido abordada ya en relación a casos concretos. José Mario Martín Flores afirmó ya que "se ha creado una literatura de la diáspora, la cual se puede detectar en tres distintas

${ }^{1}$ El caso de España y la construcción de un discurso literario de restitución de la memoria y la dignidad ha sido abordado por proyectos y redes de investigación internacionales como "La memoria novelada" (http://memorianovelada.au.dk/es/), impulsada desde la Universidad de Aarhus (Dinamarca) y que ha producido la serie de libros La memoria novelada en los que se ha abordado por extenso la novela contemporánea española como parte del proceso memorístico de la Guerra Civil y el Franquismo.

2 Puesto que nuestra intención no es focalizarnos en autores concretos ni en literaturas nacionales específicas, omitiremos tratar casos específicos ni referirnos a la situación político-social de cada país. No es nuestra intención tratar América como un todo uniforme ni obviar que algunos gobiernos están lejos todavía de alcanzar la democracia y conceder libertades plenas a los ciudadanos, pero no es nuestro ánimo abordar cuestiones políticas, sino literarias. La diáspora latinoamericana ha sido tratada desde la confluencia de los elementos sociológicos y literarios en relación a las últimas décadas en estudios recientes, como Fornet (2000) y Manzoni (2007), con especial atención a la literatura cubana y, en el caso de Manzoni, en particular en el autor Reinaldo Arenas. 
generaciones" (Martín Flores en Wences, 2008) y que, en consecuencia, ha construido ya una tradición rastreable e identificable.

Esta tradición no debe limitarse, sin embargo, a la tradición impresa ni a la de los autores más próximos por su edad a las épocas más complejas y oscuras de cada uno de sus respectivos países. En la producción literaria de la diáspora en español resulta interesante señalar que, como han identificado proyectos de investigación, hay una mayor producción de autores latinoamericanos publicando en España que autores españoles en Latinoamérica, algo que es consecuencia directa del volumen poblacional de un lado y otro del océano, pero también de los modelos industriales de edición, publicación y distribución del libro (Millán, 2015). Con todo, hay una extensa y considerable nómina de autores de un lado y otro cuyas voces se han proyectado desde la diáspora, como la reciente categoría de Patricio Pron (2015) con una cincuentena de nombres del siglo XX (y en menor medida del XXI) de países como España, Uruguay, Chile, Paraguay, Cuba o Argentina... por lo que ni siquiera pretendía ser exhaustiva, sino meramente ilustrativa del fenómeno y que reoganizamos a continuación para dividirla por criterios estrictamente geográficos (países ordenados alfabéticamente y respetando el orden de enumeración de Pron):

Argentina: Griselda Gambaro, Roma Mahieu, Arnaldo Calveyra, Julio Cortázar, Bortnik, Mempo Giardinelli, Manuel Puig, Humberto Costantini, Jorge Boccanera, Alicia Kozameh, Josefina Ludmer, Clara Obligado, Osvaldo Lamborghini, Ricardo Piglia, Alfredo Arias, Juana Bignozzi, Rodrigo Fresán, Juana Salabert, Sergio Chejfec, Ariana Harwicz, Ezequiel Zaidenwerg, Samanta Schweblin, Sylvia Molloy, Lázaro Covadlo, Eduardo Berti, Nora Catelli, Edgardo Dobry, Enrique Lynch, Graciela Montaldo, Reinaldo Laddaga, Andrés Neuman, Matías Capelli y Martín Caparrós.

Chile: José Donoso, Jorge Edwards, Antonio Skármeta, Luis Sepúlveda, Isabel Allende, Roberto Bolaño, Ramón Griffero y Carlos Cerda.

Cuba: Reinaldo Arenas, Heberto Padilla, Armando Valladares, Jorge Valls, Matías Montes Huidobro, Pedro R. Monge Rafuls, José Triana, Guillermo Cabrera Infante y Severo Sarduy.

España: Max Aub, Ramón J. Sender, Arturo Barea, Manuel Andújar, Rafael Alberti, Pedro Salinas, Luis Cernuda, Emilio Prados, Manuel Altolaguirre, Paulino Massip, Claudio Sánchez Albornoz, María Teresa León, Juan Ramón Jiménez, José Ortega y Gasset, Francisco de Ayala, Rosa Chacel y Ramón Gómez de la Serna.

Paraguay: Rubén Bareiro Saguier, Augusto Roa Bastos y Gabriel Casaccia.

Perú: Alfredo Bryce Echenique, Manuel Scorza y Julio Ramón Ribeiro. 
Uruguay: Mario Benedetti, Carlos Rama, Eduardo Galeano, Juan Carlos Onetti, Cristina Peri Rossi, Fernando Ainsa, Ángel Rama, Emir Rodríguez Monegal y Carlos Manuel Varela.

En el caso de la literatura digital, la ubicuidad de la red y la disolución del componente fronterizo como distintivo y condicionante máximo (salvo en los casos en los que se censura el acceso a la red) podemos establecer una nómina fundamental de autores hispanoamericanos que, o bien viven y escriben desde España con este país como su residencia o pasan en él largos periodos que incluiría, entre otros, los siguientes nombres: Hernán Casciari, Edith Checa, Doménico Chiappe, Belén Gache, Eugenio Tisselli, y Leonardo Valencia (por orden alfabético). Seleccionamos estos nombres por representar diferentes tipos de escritura en línea, diferentes orígenes y diferentes situaciones vitales que los vinculan con España.

En el espectro creciente de la escritura digital, interactiva e hipermedia resulta de especial relevancia el fenómeno de la narrativa del yo, es decir, aquella que se enmarca en el eje complejo y en ocasiones retorcido de la autoficción, la (auto)biografía y todos los puntos intermedios del pacto ambiguo (Alberca, 2007), que tiene su impacto en la narrativa del yo digital, en la que los recursos de construcción de identidad en la red se orientan hacia perseguir el engaño del lector con la intención de que autor, narrador y protagonista son el mismo ente, como ya había establecido Lejeune (1991). En esta literatura digital los recursos escriturales y de construcción de presencia se plantean para que el lector crea que la mascarada digital a la que asiste como receptor es un texto autobiográfico mediante la capacidad demiúrgica de la avatarización de la identidad en línea (Escandell, 2012).

\section{Autoficción y pactos ambiguos}

La avatarización constituye una negación de la autoría real en la que la identidad en línea ficcionalizada por completo o concebida como una alteridad autoficcional del yo autoral ayuda a definir una relación no intervenida por el componente fictivo entre quien emite el testimonio biográfico y los usuarios-lectores de las diferentes redes sociales, blogs u otros espacios de publicación en línea. Estos lectores pueden dividirse, asimismo, entre los crédulos que no cuestionan la veracidad de lo que leen, los escépticos que la ponen en duda y los que participan en ella aun sabiendo que es una ficción. Por supuesto, esta categorización de los lectorescomentaristas del blog solo tiene sentido mientras la acción que narra se desarrolla y se mantiene el engaño: una vez se declara o descubre la verdad (esto es, se sabe ya sin duda alguna que los hechos narrados no son experiencias vitales de un bloguero, sino una ficción creada por un autor literario) la relación con los lectores pasa a situarse en los pactos de ficción 
tradicionales. Y si esta credulidad es factible por parte de los receptores es porque en el contexto digital se ha abrazado socialmente la extimidad, es decir, la tendencia a hacer público lo íntimo compartiendo los momentos vitales, pensamientos, etc., en toda suerte de red social, como pronosticó Echeverría:

La principal novedad de la organización telepolitana estriba en haber transformado el ámbito doméstico en algo público, aunque sólo sea de manera unidireccional. Gran parte de lo que pasa a ser público en las plazas de Telépolis ha sido elaborado para ser consumido en las casas. La invasión de lo privado por lo telepúblico, siendo un fenómeno ampliamente extendido, puede traspasar en los próximos años un nuevo umbral, llegando a los ámbitos estrictamente íntimos, ya no sólo privados. (1994: 161)

Esta autoficcionalización avatarizada o la construcción ficcional plena a través del recurso avatárico se asume como hecho aceptable en la red y no necesariamente literario ni falso (en cuanto literario) dado que en la sociedadred que hemos desarrollado se asume con normalidad que la vida se convierte potencialmente en un hecho narrativizable y susceptible de ser espectacularizado y expuesto (grabado, fotografíado, etc.). Esto implica un conocimiento implícito de que habrá, al menos, un cierto grado de discrepancia entre la imagen proyectada y la imagen real de nosotros mismos y quienes nos rodean, en la realidad y en la virtualidad.

Cuando se trasciende una frontera difusa y poco o nada definida sobre el volumen o gravedad de estas distorsiones de la realidad se entra en el terreno de la autoficción; cuando el bloguero que cuenta su vida es por entero fictivo, entonces se ha entrado en el campo del simulacro digital y el engaño con intención literaria para exponer una ficción plena como si fuera un hecho real más allá de los pactos de ficción que se pudieran establecer o de la suspensión de la credulidad de los receptores.

Se trata de un desenmascaramiento voluntario o forzado por parte del autor que redefine la relación con la comunidad que se ha formado en torno a la obra, pero sus consecuencias no son necesariamente negativas. Así, Hernán Casciari señaló que, según progresa el desarrollo de la obra blogonovelesca, el propio autor puede dar pasos en esa dirección sin que haya perjuicios de tal modo que "más tarde, cuando el lector ya esté habituado y no le importe — cuando hayamos conseguido "transportarlo"podremos quitar algunos velos sin peligro" (2006: 174). En el formato libro (tanto como plataforma origen del acto literario o como resultado de la adaptación de una narración en línea), lógicamente, no se dan los canales de comunicación que sí existen en la red y como texto estático presenta ese desenmascaramiento desde el principio: en el mismo momento en que se vende como obra de ficción o el nombre del autor aparece en la portada ya 
sabemos que no se trata de un diario personal real. Ante una situación como esa nos encontraríamos, por tanto, ante una situación mucho más próxima al pacto ambiguo descrito por Alberca que al hoax, que se basa en la impostura de lo real: una hiperrealidad que se superpone gracias a la mediación de los recursos de constitución de la identidad digital a los referentes reales de individuo y autoría.

El pacto ambiguo se constituye sobre el ideal de desdibujar los límites entre lo ficticio y lo real, un acto performativo cuyo objetivo "consiste en mezclar y en confundir los límites de lo real y lo inventado" (Alberca, 2007: 34). Esto mismo es lo que hemos visto en las novelas de autoficción, que también han generado reacciones singulares entre lectores que no han identificado claramente la diferencia entre el yo real del autor y el yo ficticio, que es personaje de las obras falsamente autobiográficas, y puede incluso haber enconadas polémicas entre autores o críticos. Como en otras obras de la autoficción se desdibuja la frontera entre la ficción y la realidad, lo que puede dar lugar a cierta confusión entre el ente autor y el ente personaje por parte de los receptores de la obra.

\section{El rastro de la diáspora y la avatarización: Casciariy Guerrieri}

La literatura propia de la diáspora conduce hacia un relato prototípicamente vinculado con la reconstrucción de la experiencia migratoria desde la circunstancia vital de la misma, lo que conduce a la esencia del choque cultural y la nostalgia del hogar abandonado como topoi predominantes, en particular cuando se trata de conducir la identidad narrativa hacia nuevas concepciones del yo, sean estas impostadas completamente o autoficcionalizadas. Y es que poca duda cabe de que se trata de experiencias vitales de gran relevancia y que marcan el devenir de sus figuras literarias: no puede ser considerado como anómalo que sus países (sus conflictos, sus realidades y su visión desde la distancia) y la experiencia del inmigrado (el nuevo país, su visión desde la cercanía del extraño, su realidad y sus conflictos) sean tema recurrente en sus obras o que se pueda rastrear un poso de lo migrante en sus escrituras.

En la cibersociedad, es decir, en el encuentro o espacio social que está marcado por la no-localización plena de la supermodernidad (Augé, 1992), es un espacio de inversión de lo real y carnal dando lugar a una realidad sensible telematizada:

La consecuencia más inmediata era la inversión de lo real de modo que todo se aproximase, modificando las relaciones milenarias entre lo próximo y lo distante. Una serie de síntomas permitía entender lo que estaba pasando: la huida de los dioses en Hölderlin, la muerte de Dios en Nietzsche, así como la red ferroviaria o el sistema postal; todo ello indi- 
caba que la distancia, espacial o temporal, estaba menguando (Bragança de Miranda, 2010: 205).

La disminución de la distancia física, intelectual y relacional se proyecta en red a una colectividad conectada (aunque sola tras la pantalla del dispositivo que les une con la red en una relación simbiótica), como pronosticaba también Walter Benjamin a raíz de la radio (2011). En este contexto resulta necesaria una nueva reconciliación entre la esfera de virtualidad y la mental del autor en un proceso que cobra una importancia creciente en la sociedad moderna con una hegemonía que trasciende incluso la macrovisión supranacional (Lefebvre, 2008). Simultáneamente, la microvisión local deja de ser estrictamente ese elemento de oposición, pues modifica su percepción limitada a través de la emisión de mensajes sin barreras físicas mediante la distribución digital de la información. Se configura así un espacio, el digital, que debe ser percibido como el nuevo espacio a conquistar, tanto por el conocimiento como por las personas, siguiendo el nuevo espacio de producción de presencia lefebvriana. Para Goldsmith (2005), si algo no existe en internet, simplemente no existe, por lo que la virtualidad conectada es el espacio de conquista social, intelectual y cognoscitiva que debe perseguirse. Es una visión fenomenológica del hecho presencial en la red donde no hay, en un sentido clásico, forma (Gestalt) donde "la conciencia no está integrada por elementos a la manera de las cosas exteriores, es un todo en el cual los elementos no tienen existencia separable" (Merleau-Ponty, 2011: 39). La ubicuidad digital diluye la forma, la neutraliza y da lugar a una distancia dramática que afecta a la experiencia perceptiva.

En la narrativa del yo basada en la avatarización de la identidad, como la blogoficción y la narrativa de redes sociales que se canalizan mediante perfiles digitales como ejes principales de la organización y composición textual, el avatar conquista los espacios de producción de presencia del autor, lo que restringe o elimina por completo la capacidad de presencialidad del autor en su misma obra si quiere que el hoax de la identidad del personaje (o el constructo real-ficcional de la autoficcionalización). Los personajes, por tanto, permiten una emulación del relato autobiográfico o bien una simulación plena, un simulacro baudrillardiano que se basa en una tecnoestética de la suplantación de la realidad, potencialmente factual y sin duda alguna probable y creíble por la aproximación a la sustitución de los signos de lo real. Se simula una presencialidad, un presente (un tiempo de escritura y lectura compartido en directo) y un mundo compartido con los receptores a partir de la imitación plena de los códigos y signos de los espacios de construcción de presencia del individuo extimista de la red. Es decir, o se construye una identidad autoficcional o una identidad completamente ficcionalizada, pero en ambos casos se busca la suplantación de la identidad del usuario de internet en redes sociales, blogs y espacios afines de la sociedad-red. Así pues, es un arte del fingimiento que responde a las claves de memoria (real o impostada), expe- 
riencia e identidad (fictivas), identidad (avatárica), espacio (real, ficcional y digital), cuerpo (tecnocuerpo) y agenda (objetivo ficcional) descritas por Smith y Watson (2001).

En el caso de Hernán Casciari, se trata de un autor argentino (Mercedes, 1971) residente en España desde 2000. Su publicación en internet más destacada es Más respeto, que soy tu madre, blogonovela escrita y publicada entre 2003 y 2004. ${ }^{3}$ Como extranjero, Casciari busca el contacto con sus amistades próximas retratando a una mujer mercedina que lidia con una familia cómica y desestructurada. Lo hace narrando los devenires de una vida humorística que se asienta en el retrato deformado de la realidad de esa región argentina. No es de extrañar, por tanto, que se filtren los propios recuerdos y añoranzas del autor, que toma una perspectiva de lector (pues asume en el juego de máscaras avatáricas que la autora es Mirta Bertotti). Afirma Casciari en el prólogo del blog que "me divertí mucho, cada mañana de 2003, leyendo con el privilegio de ser el primer lector- unas historias que me acercaban al lugar donde nací y por el que sentía, y siento, una gran nostalgia" (Casciari, 2009b). ${ }^{4}$ Esta línea de pensamiento la podemos seguir en el prólogo de la edición impresa para el mercado Argentino en su versión de 2009, que describe el texto vertido del blog a la hoja impresa como "un documento de la vida cotidiana $[\ldots]$ escrito de puño y letra por una señora de mi pueblo que bien podría haber sido mi madre" (2009: 12). La figura de la madre, canalizada a través del avatar de Mirta Bertotti, protagonista de la blogonovela y seánce de los recuerdos en la distancia de la tierra natal: la creación literaria de la narrativa de este falso diario de Mirta, esta narrativa del yo intervenida por el avatar, es un proceso cicatrizador en la distancia. Relata Casciari que:

Cuando llegué a España en el año 2000 no podía escribir porque los regionalismos me tenían paralizado. Yo siempre había escrito como se habla en Argentina y me sentía incapaz de hacerlo a la manera española. Estaba claro que no podía hacer una novela dirigida al público español hablando de "vos", pero tampoco me salía usar la palabra "tú", porque ya desde pequeño, cuando en mi país leía libros impresos en España, el castellano que se habla aquí me parecía tremendamente forzado.

Así que estuve dos años callado, tratando de adaptarme a los códigos de aquí. Yo hago humor, y no se puede hacer humor si no se dominan totalmente los códigos. Mientras, descubrí que existían los blogs, y abrí uno en septiembre de 2003 como un chiste para mis amigos argentinos.

3 Publicada en formato libro en España, Argentina y México en diversas ediciones (Escandell, 2013), puede leerse todavía en formato blog en la siguiente dirección: http:/ / mujergorda.bitacoras.com

4 Aunque inserto en la blogonovela, escrita entre 2003 y 2004, el prólogo en realidad se prepara para el rediseño de la bitácora que se hizo en enero de 2009. Disponible en http://mujergorda.bitacoras.com/cap/prologo.php 
Así nació la familia Bertotti, y fue entonces que me di cuenta de que determinados tipos de humor, determinadas historias, son universales. (Casciari citado en Telecinco, 2005)

Como extranjero, Casciari busca el contacto con sus amistades próximas retratando a una mujer mercedina que debe sufrir a una familia que muchos asistentes sociales calificarían como desestructurada. Lo hace narrando los devenires de una vida humorística, si bien esta se asienta en el retrato deformado de la realidad de esa región argentina. No es de extrañar, por tanto, que se puedan filtrar los propios recuerdos y añoranzas del autor, que toma una perspectiva de lector (pues asume en el juego de máscaras avatáricas que la autora es Mirta Bertotti). La visión del emigrado que se filtra a través de Mirta es la de la nostalgia: se trata de una mirada hacia atrás, hacia la Argentina dejada por Casciari al asumir su nueva vida en Barcelona. La madre y la patria se encarnan a través de los personajes, que surgen del pasado mercedino del autor de tal manera que la ficción toma la forma de una narración mediada por la voz del no-emigrado desde la lejanía del emigrante que se enfrenta, así, a su propia voz.

La figura del emigrante no es rara en la escritura digital y transmedia de Casciari: el autor argentino llevó a cabo el proyecto del blog oficial de la serie de televisión Mi querido Klikowsky, emitida entre 2005 y 2008 en la televisión autonómica vasca ETB. ${ }^{5}$ El blog ${ }^{6}$ se planteaba como el diario en línea personal de Saúl Klikowsky y ayudaba a complementar la historia principal de la serie: la vida de un argentino que trabajaba en Londres pero que, por amor, viaja a Euskadi. El papel de Saúl era interpretado por el actor argentino Martín Gervasoni pero su voz en la red era la de Casciari. Eso sí, el contexto del personaje ya existía antes de que se creara la bitácora: su vida, en efecto, existe fuera del blog dentro de la serie de televisión. No obstante, el blog no es una adaptación, ni una sinopsis, ni una guía de capítulos: Casciari avatariza a Saúl Klikowsky y crea sus propios contenidos, aunque el resultado es más próximo a un fotolog que a una blogonovela o a un blogopersonaje al uso. Asimismo, el blog, como la serie, tenía un eje destacado de su serialización en el humor de situación su rasgo genérico principal y la visión del extranjero y su extrañamiento ante la cotidianidad común para los demás personajes (y los televidentes y los lectores).

Marcelo Guerrieri, originario de Argentina, donde nació en 1973, residió varios años en Suecia y otras zonas de Europa entre los años 2005 y 2008. En este periodo lejos de su país natal firma la blogonovela Detective bonaerense, que

\footnotetext{
${ }^{5}$ La serie fue emitida a nivel nacional por canales temáticos como Paramount Comedy bajo producción de Globo Media.

${ }^{6} \mathrm{El}$ blog se publicaba en la dirección siguiente, pero dejó de mantenerse y estar colgado en la red desde que terminó la serie, razón por lo que en la actualidad redirige a una página general de la televisión autonómica vasca: http:/ /www.klikowsky.com
} 
se publica durante el año 20067 . En este caso, el detective Aristóbulo García, el personaje avatárico, investiga a un criminal en Suecia; sin embargo, debemos tener en consideración que se declara desde un primer momento que es un texto fictivo (en la cabecera leemos que se define como blogonovela), lo que contravendría parcialmente los preceptos de la simulación avatárica: se crea el personaje bajo la narración testimonial en primera persona en el espacio del blog, pero sin pretender ficcionalizar la vida del autor ni asumir que es un blog de un usuario al uso: de ahí la declaración de ficcionalidad expresa. Sin embargo, sus recursos narrativos son los mismos que en las blogoficciones que mantienen el hoax a diferentes niveles.

En el texto de Guerrieri el protagonista es el avatar Aristóbulo García, un investigador argentino que intenta resolver un crimen atrapando a un delincuente en la ciudad de Uppsala, por lo que nos traslada indirectamente a la situación vital del autor: un argentino en Suecia. La blogonovela se escribe y publica durante la estancia de Guerrieri en el país escandinavo e integra, como no podía ser de otro modo, a Aristóbulo como trasunto del autor. Se sumerge, de este modo, en una realidad que es exógena tanto para el autor como para el protagonista de la novela de detectives. La actividad literaria de Guerrieri en Suecia se canalizó a través de la impartición de talleres literarios en asociaciones culturales latinas, la aparición en emisoras de radio del país, etc., por lo que escribir una novela en blog en la que se filtrara, a través de un personaje ficcional, su experiencia migrante resulta una acción coherente con su trayectoria profesional y literaria.

Pero ¿no es posible acaso ver en el niño burbuja de Belén Gache un trasunto de la identidad en su fragilidad en el emigrado que se sumerge en una nueva situación cultural y social? Gache (Buenos Aires, 1960) es una autora hispanoargentina que actualmente reside en Madrid y que en 2004 escribe y publica la blogoficción El diario del niño burbuja, ${ }^{8}$ una obra que se aleja de la imitación, suplantación y simulación de la blogoficción para construir un mundo en el que el protagonista es un joven chico anatómicamente marcado por su apariencia de burbuja. Este niño tiene una relación compleja con su circunmundo, lo que incluye sus relaciones familiares, que son consecuencia directa de saberse diferente y la percepción constante por el mundo que le rodea de que es la anomalía en el sistema. Un señalamiento que podemos vincular con el del emigrado y, en el caso de Gache como una potencial dislocación por su origen (su familia materna es andaluza y la paterna gibraltareña, pero ella nació en Argentina). Explica Gache que:

El proyecto Bubbleboy fue concebido para ser realizado en internet, mediante 100 posts, realizados durante cien días consecutivos. Cada uno de

${ }^{7}$ Esta blogonovela puede leerse en línea en la siguiente dirección:

http:/ / www.detectivebonaerense.blogspot.com.es

${ }^{8}$ Puede leerse en la web a través de la siguiente dirección:

http://bubbleboy.findelmundo.com.ar 
ellos constaría de una imagen encontrada en un buscador de imágenes y de un texto breve. [...] Se constituyó como un texto a la deriva y en proceso, sin una trama o dirección preestablecida.

Burbuja, frágil e inconstante, está en continua amenaza de desaparición. $\mathrm{Al}$ igual que las burbujas flotan en un hiperespacio constituido por múltiples dimensiones, Bubbleboy habita el ciberespacio, lugar igualmente multidimensional que propone una nueva espacialidad y una nueva temporalidad sin órdenes lineales o causales precisos. (2004)

El niño burbuja está, como indica la autora, bajo una amenaza de desaparición constante, pues es frágil: un juego de equilibrios con la vida en la que la propia identidad es una amenaza y un condicionante pese a la individualidad y singularidad de la misma. El cuerpo virtual, avatarizado, del niño burbuja es un mediador entre el yo autoral y el mundo ficcional planteado: como reflexionó la propia Gache, "el usuario del mundo virtual se vale del cuerpo mediador del avatar para moverse dentro del mismo y también para producir sus enunciados" (2009: 126). Se experimenta, de este modo, una otredad que es válida también para separar la situación propia, alejar la perspectiva y ver el circunmundo con otros ojos, que no son los propios, pero que comparten una visión del mundo (al menos, parcial) para redibujar la realidad y a uno mismo mediante la observación de la ficcionalidad.

\section{Conclusiones}

La narrativa del yo en el contexto digital de la avatarización nos permite rastrear una doble posibilidad discursiva del emigrado a través del proceso creativo-emocional de su escritura literaria. Por un lado, tenemos el ejemplo de Hernán Casciari a través del personaje de Mirta como una mirada hacia el pasado en la que se rememora un lugar que ya no es el que se habita; por otro, Marcelo Guerrieri con Aristóbulo procesa la carga emocional a través del posicionamiento de su personaje en la misma situación de extrañamiento que vive, reflejando su presente filtrándose a través de la ficción. Así, donde uno disloca la voz narrativa para viajar al hogar, el otro la acerca al reflejo de su realidad más inmediata. En los dos casos, las voces asumidas en sus composiciones narrativas se marcan por el hecho migratorio y la situación de diáspora vivida por los autores: su obra parece filtrar una situación vital que, si bien no tiene los condicionantes del exilio, sí refleja los de la migración y la nostalgia.

Esto nos lleva a asumir que los resultados de la blogoficción se pueden someter al análisis de la memoria de la sociedad y del autor literario desde la perspectiva de la memoria y la diáspora. Como narrativas del yo mediadas demiúrgicamente por el personaje-avatar, las motivaciones pueden ser equiparables tanto por parte del personaje como por el autor pues sus voces no 
son necesariamente discordantes y la disonancia entre autor y personaje es parte, en todo caso, del juego de enmascaramiento de este tipo de narrativa digital.

Hay, por tanto, un motor social y emocional que instiga parte de la narrativa del yo en internet basada en la avatarización y que tiene sus engranajes insertos en la diáspora latinoamericana.

\section{Referencias}

ALBERCA, Manuel (2007). El pacto ambiguo. De la novela autobiográfica a la autoficción. Madrid: Biblioteca Nueva.

AUGÉ, Marc (1992). Non-Places. An Introduction to Supermodernity. Trad. John Howe. Londres: Verso.

BENJAMIN, Walter (2011). La obra de arte en la era de su reproducción técnica. [1939]. Trad. Silvia Fehrmann. Buenos Aires: El Cuenco de Plata.

BRAGANÇA DE MIRANDA, José (2010). "El final de la distancia: el surgimiento de la cultura telemática." Ontología de la distancia. Filosofías de la comunicación en la era telemática. Ed. G. Aranzueque. Madrid: Abada. 203224.

CASCIARI, Hernán (2006). "La ficción on line. Un espectáculo en directo." La blogosfera hispana: pioneros de la comunicación digital. Ed. J. M. Cerezo. Madrid: France Telecom. 171-179.

- (2009). Más respeto, que soy tu madre. Buenos Aires: Plaza \& Janés. (2009b). "Prólogo. Mirta y yo." Más respeto, que soy tu madre. 25 jul. 2015. http://mujergorda.bitacoras.com/cap/prologo.php ECHEVERRÍA, Javier (1994). Telépolis. Barcelona: Destino.

ESCANDELL MONTIEL, Daniel (2012). "El escenario virtual de la blogoficción. Construcción avatárica en la narración digital." Nuevos hispanismos. Para una crítica del lenguaje dominante. Ed. J. Ortega. MadridFrankfurt: Iberoamericana-Vervuert.

(2013). “Argentina, España, México. Edición pluricéntrica en la obra de Hernán Casciari.” Diálogos Latinoamericanos 20: 97-118.

FORNET, Ambrosio (2000). Memorias recobradas. Introducción al discurso literario de la diáspora. Santa Clara: Ediciones Capiro.

GACHE, Belén (2004). "El diario del niño burbuja." belengache.net. 25 jul. 2015. http://bubbleboy.findelmundo.com.ar

(2009). "Possible selves, de las escrituras del yo al yo como otro." Versión 22: 115-128.

GOLDSMITH, Kenneth (2005). "If It Doesn't Exist on the Internet, It Doesn't Exist.” Buffalo.edu. 25 jul. 2015.

http://epc.buffalo.edu/authors/goldsmith/if_it_doesnt_exist.html

LEFEBVRE, Henri (2008). The Production of Space. [1974]. Trad. Donald

Nicholson-Smith. Malasia: Blackwell Publishing. 
LEJEUNE, Philippe (1991). "El pacto autobiográfico." Anthropos: Boletin de información y documentación 29: 47-62.

MANZONI, Celina (2007). "Diáspora, nomadismo y exilio en la literatura latinoamericana contemporánea." University of Texas Digital Repository. 25 jul. 2015. http://hdl.handle.net/2152/4102

MERLEAU-PONTY, Maurice (2011). La fenomenología y las ciencias del hombre. [1958]. Buenos Aires: Prometeo Libros.

MILLÁN, José Antonio (2015). "Separados por un mismo idioma. El mercado del libro en español." Letras libres: 44-50.

PRON, Patricio (2015). “Ampliación del campo de batalla." Eterna Cadencia. 25 jul. 2015. http://blog.eternacadencia.com.ar/archives/43436

SMITH, Sidonie y Julia Watson (2001). Reading Autobiography: A Guide for Interpreting Life Narratives. Minneapolis: University Of Minnesota Press.

TELECINCO (2005). "El ama de casa más leída de Internet se llama Hernán Casciari." Informativos Telecinco. 4 nov. 2009.

http://www.informativos.telecinco.es/entrevista/casciari/mujergorda/d n_9367.htm

WENCES MINA, Marisol (2008). "Migración a EU ha creado una literatura de la diáspora: experto.” La Jornada - Guerrero. 25 jul. 2015.

http://www.lajornadaguerrero.com.mx/2008/07/29/index.php?section $=$ cultura\&article $=013 \mathrm{n} 1 \mathrm{cul}$

(C) 2016 Daniel Escandell Montiel.

Licensed under the Creative Commons Attribution-NoncommercialNo Derivative Works 4.0 International (CC BY-NC-ND 4.0). 